\title{
A Prospective Randomized Study of the Safety and Efficacy of Transforaminal Lumbar Interbody Fusion Versus Posterior Lumbar Interbody Fusion in the Treatment of Lumbar Spondylolisthesis: A Cost utility from a Lower-middle-income Country Perspective and Review of Literature
}

\author{
Nasser El-Ghandour ${ }^{1}$ (D), Mohamed Sawan ${ }^{1}$, Atul Goel ${ }^{2}$, Ahmed Assem Abdelkhalek ${ }^{1}$, Ahmad M. Abdelmotleb ${ }^{1}$, Taher Ali $^{1}$ iD \\ Mohamed S. Abdel Aziz ${ }^{3}$, Mohamed A. R. Soliman ${ }^{1 *}$ (D) \\ ${ }^{1}$ Department of Neurosurgery, Faculty of Medicine, Cairo University, Cairo, Egypt; ${ }^{2}$ Department of Neurosurgery, Seth G. S. \\ Medical College, King Edward VII Memorial Hospital, Parel, Mumbai, India; ${ }^{3}$ Department of Neurosurgery, Beni-Suef University, \\ Beni-Suef, Egypt
}

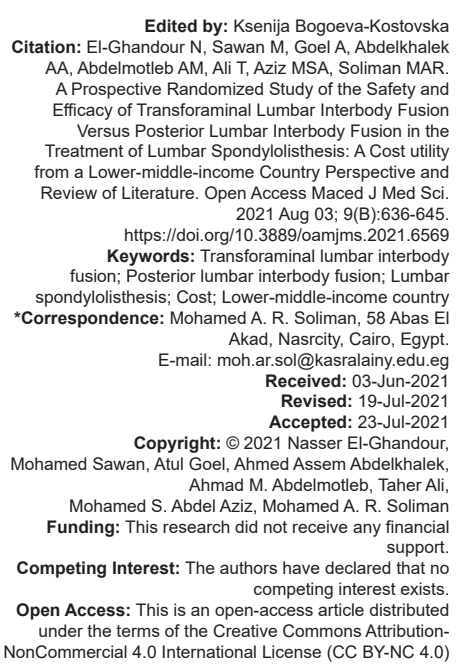

\begin{abstract}
BACKGROUND: The safety and efficacy of transforaminal lumbar interbody fusion (TLIF) and posterior lumba interbody fusion (PLIF) in lumbar spondylolisthesis have not been validated in many prospective randomized trials.

AIM: We aimed to validate the safety and efficacy of TLIF and PLIF surgery in lumbar spondylolisthesis using the clinical, radiographic, and cost-utility outcomes.

METHODS: The data of surgically treated single-level spondylolisthesis patients were randomized prospectively into two groups. The groups were compared regarding demographics, perioperative complications, hospital stay, total expenditure, fusion rate, and clinical outcomes (visual analog scale, Oswestry disability index, Zurich claudication scale, and Odom's criteria). A review of literature was done to compare the outcomes with the ones from higherincome nations.

RESULTS: Thirty-three patients underwent prospective randomization. The improvement in the clinical outcomes at 12-month follow-up showed improvement in the TLIF group more than the PLIF group but with no significant difference. The mean operative time was significantly longer in the PLIF ( $p<0.05)$, also, the blood loss was significantly less in the TLIF $(p<0.001)$. The complications frequency did not show any statistical significance between both groups and no significant difference in the patient's post-operative patient satisfaction $(p=0.6)$. The mean hospital stay was non-significantly longer in the PLIF ( $p=0.7$ ). At 12-month follow-up, 93.3\% of the TLIF patients were fused versus $86.7 \%$ of the PLIF $(p=0.5)$. The total cost of the TLIF was significantly less $(p<0.001)$. CONCLUSION: Both PLIF and TLIF could achieve similar fusion rates and clinical satisfaction in the management of lumbar spondylolisthesis. The TLIF group was significantly better in terms of financial burden, operative time, and blood loss.
\end{abstract}

\section{Introduction}

Degenerative spondylolisthesis describes the forward shift of the vertebra above in relation to the vertebra below [1]. Degenerative lumbar spondylolisthesis usually presents with leg pain (whether neurogenic claudication or radicular pain), with or without low back pain [1]. Surgery is indicated in case of progressive neurological deficits or after the failure of conservative management including physical therapy [1]. In unstable spondylolisthesis, management includes decompression of nerve roots alongside instrumentation which consists of pedicle screw fixation, interbody cages, or a combination of both [2]. Interbody cages can be done from a posterior approach using posterior lumbar interbody fusion (PLIF) and transforaminal lumbar interbody fusion (TLIF) [3]. The bilateral PLIF technique for instrumented spinal fusion was introduced in 1953 by Cloward [4]. TLIF was first introduced by Harms and Rolinger who used a bone graft packed in the titanium cage, which was inserted through a unilateral transforaminal route into disc space [5]. Further development of this technique was done by Harms and Jeszenszky and was described in detail in 1998 [6]. Nowadays, with the introduction of new instrumentation, PLIF and TLIF techniques are widely used [7]. The TLIF procedure was developed to reduce the risks associated with a PLIF procedure [7], [8]. For both techniques, additional pedicle screw fixation is used [7]. Several studies have compared the costs, safety, and outcome of posterior lumbar fusion alone and with the addition of an interbody cage (PLIF/TLIF) [9], [10], [11], [12]. 
However, to the best of our knowledge, this is the first study to directly compare the costs of PLIF and TLIF surgery. Furthermore, this study aims to assess the clinical and radiographic outcomes and cost difference between PLIF and TLIF in a low-/low-middleincome nation and to compare it to the current literature from higher-income nations.

\section{Materials and Methods}

\section{Study design and population}

A randomized prospective control trial was conducted on 33 cases of single-level spondylolisthesis which were surgically managed in the period between January 2018 and April 2019 in the Neurosurgery Department at Cairo University Hospitals. Patients were assigned to a TLIF or PLIF in a ratio of $1: 1$. The inclusion criteria were patients above the age of 18 years suffering from symptomatic lumbar spondylolisthesis that did not respond to routine conservative treatment, besides radiological finding suggestive of Grade I or II lumbar spondylolisthesis. The exclusion criteria were patients with two or more level disease, Grade III and IV spondylolisthesis, osteoporosis/osteopenia, or those with previous spine surgical intervention. The patients that fit into these inclusion criteria were randomized after they were completely assessed by a neurosurgery specialist. This was followed by a detailed explanation of the potential surgical approaches, randomization procedure, and required follow-ups and investigations by the neurosurgery specialist to the potential candidates. Informed consent was signed on agreement of the candidate to participate. This was followed by the randomization of the candidate into one of the two surgical approaches. A sealed envelope was used in the procedure selection by the study coordinator. Patients $(n=3)$ who lost follow-up or died during the follow-up were excluded from our analysis.

\section{Data collection and outcomes}

All patients' data including the demographics were prospectively collected and all patients were subjected to complete history taking and neurological examination on admission by a neurosurgery specialist followed by self-filled patient-reported outcome measures (PROMs) questionnaires such as visual analog scale (VAS) for back and leg pain (ranges, 0-10), Zurich claudication scale (ZCS) for neurogenic claudication (range, 1-4), and Oswestry disability index (ODI) for disability (range, 0-100). All the patients were investigated in the form of pre-operative routine preoperative laboratories, X-ray lumbar spine (dynamic views), and magnetic resonance imaging of the lumbar spine.
The primary outcome of this study was to calculate the total cost of surgery in both groups. The total cost included implants (screws and cages) which were from the same company in both groups, the salary of medical and nursing personnel, hospital stay (medications and services) at Cairo University Hospitals (public hospital). The cost was calculated in Egyptian Pounds and then converted to American Dollars to compare it to the current literature. Furthermore, we asked some of the neurosurgeons about the average total cost of surgery in their private practice.

Secondary outcomes included rate of perioperative complications (infection, hematoma, dural tear, nerve injury, vascular injury, or 30 days mortality), operative time, estimated blood loss (EBL), hospital stay, pre- and post-operative (1 year) PROMs (VAS, ODI, and ZCS scores), Odom's criteria (excellent, good, fair, and poor), and fusion rate (presence of trabecular bridging bones across the fusion segment [ $>50 \%$ ] on computed tomography scan).

Patients were followed up closely by the study coordinator in the outpatient clinic at 14 days, 6 months, and 1 year and the above data were filled immediately in an Excel sheet.

\section{Study oversight}

This study was approved by the local neurosurgery department ethical committee, and informed consent was signed by all enrolled patients. The study was conducted according to the accepted protocol and was reported in accordance with Consolidated Standards of Reporting Trials (CONSORT) guidelines [13].

\section{Literature review}

The results of this study were compared with the published data comparing and discussing and in detail the costs/charges, clinical or radiographic outcomes of TLIF and PLIF surgeries at higher income nations. Non-English language studies, case reports, and case series with $<5$ patients were excluded from the study.

\section{Surgical technique}

The patients were generally anesthetized, endotracheally intubated and positioned into prone position. A low midline skin incision followed by dissection of the subcutaneous layer until vertebral fascia was exposed, a longitudinal fascial incision was done followed by subperiosteal muscles separation done through blunt dissection. The entry points for pedicle screws were exposed, then bilateral pedicle screws were applied on both sides. Screws' positions were verified by intraoperative fluoroscopy. 


\section{TLIF}

Aunilateral laminotomy and medial facetectomy were done using the Kerrison followed by unilateral excision of the ligamentum flavum. Annulotomy and discectomy were followed. The interbody distance was measured after curettage the endplates, and the insertion of the appropriate size polyetheretherketone (PEEK) cage filled with bone autograft was done. This was followed by polyaxial pedicle screw compression and closure.

\section{PLIF}

The same procedure was done as the TLIF but the laminotomy, medial facetectomy, ligamentum flavum excision, and discectomy were done on both sides followed by insertion of bilateral PEEK cages.

\section{Statistical analysis}

Continuous variables were presented in the form of mean value and standard deviation (S.D.) and compared using independent t-tests. The categorical variables were presented in the form of numbers and percentages and were compared using Fisher's exact test or Chi-square test. We analyzed the variations over a period of time using the paired Student's t-test. The statistical significance was set at a rate of $<0.05$.

\section{Results}

\section{Patient's characteristics}

A total of 33 patients were enrolled in the study, 17 were assigned to the TLIF group, and one of those patients lost follow-up and one died during follow-up for an unknown reason; 16 patients were assigned to the PLIF group, and one of those patients also lost follow-up. Hence, the per-protocol analysis included 30 patients (15 patients in each group). Considering the random allocation of both groups, the data summarized in Table 1, hence, there was matching between both groups regarding, age, sex, BMI, duration of symptoms, diseased level, and clinical presentation.

\section{Primary outcome}

The mean PLIF total costs $(\$ 711.9 \pm 27.1)$ were significantly higher compared to the TLIF group ( $\$ 641$ $\pm 22.4)(p<0.001)$. The highest total cost reimbursed by the operators involved in this study for a TLIF or PLIF case in their private practice was $\$ 6366.3$ (range, \$1276.2-6366.3) (Figure 1).
Table 1: Patient's characteristics

\begin{tabular}{llll}
\hline Parameter & TLIF group & PLIF group & p-value \\
\hline $\begin{array}{l}\text { Number } \\
\text { Mean age }\end{array}$ & 15 & 15 & \\
Sex & $45.9 \pm 9.9$ & $42.2 \pm 6.2$ & 0.2 \\
$\quad$ Male & $8(53.3)$ & $9(60)$ & 0.7 \\
$\quad$ Female & $7(46.7)$ & $6(40)$ & \\
$\quad$ Current smoker & $6(40)$ & $5(33.3)$ & 0.7 \\
Mean BMI & $32.5 \pm 2.8$ & $31.6 \pm 3.1$ & 0.4 \\
Level & $9(60)$ & $7(47.7)$ & 0.7 \\
L4-5 & $6(40)$ & $8(53.3)$ & \\
L5-S1 & $23.3 \pm 8.2$ & $22.5 \pm 6.5$ & 0.8 \\
Mean symptoms duration & & & \\
Clinical finding & $15(100)$ & $15(100)$ & 1 \\
$\quad$ Back pain & $15(100)$ & $15(100)$ & 1 \\
Claudication pain & $5(33.3)$ & $3(20)$ & 0.4 \\
Sciatica & $10(66.6)$ & $12(80)$ & 0.4 \\
$\quad$ Sensory deficit & $2(13.3)$ & $1(6.7)$ & 0.5 \\
$\quad$ Palpable step & Values are presented as the number of patients (\%) unless indicated otherwise. Mean values are reported \\
as the mean \pm SD. TLIF: Transforaminal lumbar interbody fusion, PLIF: Posterior lumbar interbody fusion, \\
BMI: Basal metabolic index, L: Lumbar, S: Sacral. & &
\end{tabular}

\section{Secondary outcomes}

At 1-year post-surgery, there was no significant difference among both treatment options regarding all the PROMs scores (VAS, ODI, and ZCS) with significant improvement in the scores of both groups compared to the pre-operative scores ( $p<0.05$ ) (Figure 2). The mean back pain and leg pain VAS at 1 year after surgery were $2.7 \pm 0.9$ and $2.3 \pm 0.8$ in the TLIF group and $2.9 \pm 0.7$ and $1.9 \pm 0.7$ in the PLIF group, respectively ( $p=0.5$ and $p=0.2$, respectively). The back and leg pain VAS had improved from baseline by $6.3 \pm 1.1$ and $5.6 \pm 1$ in the TLIF group and by 6.1 \pm 1.1 and $5.7 \pm 0.9$ in the PLIF group, respectively ( $p=0.6$ and $p=0.8$, respectively). The mean ODI at 1 year after surgery was $18.8 \pm 6.69$ in the TLIF group and $19.73 \pm 5.84$ in the PLIF group $(p=0.7)$. The ODI had improved from baseline by $48.93 \pm 9.2$ in the TLIF group and $48.4 \pm 12.48$ in the PLIF group $(p=0.9)$.

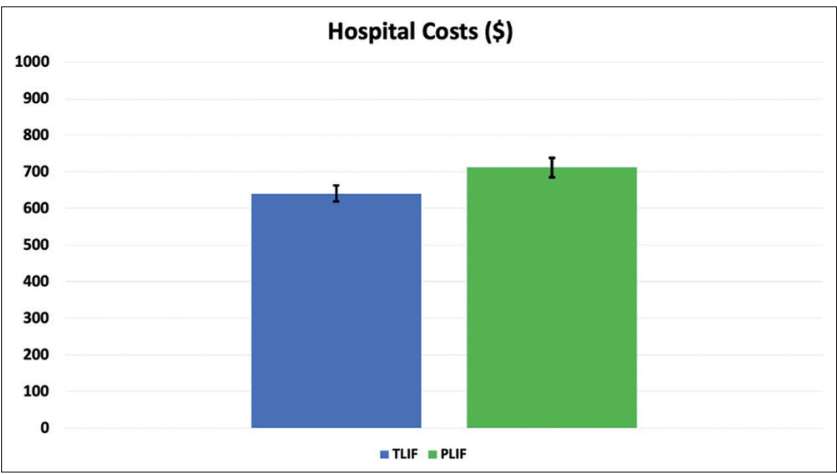

Figure 1: Bar graph depicting the total hospital costs of the transforaminal lumbar interbody fusion and posterior lumbar interbody fusion groups

In regard to $Z C Q$; the 1-year post-operative scores of symptoms severity were $2.33 \pm 0.79$ in the TLIF group and $2.47 \pm 0.81$ in the PLIF group ( $p=0.6$ ), while the physical function scores were $2 \pm 0.73$ in the TLIF group and $2.33 \pm 0.7$ in the PLIF group ( $p=$ $0.2)$. The mean patient satisfaction scores were 2.2 \pm 0.75 in the TLIF group and $2.33 \pm 0.79$ in the PLIF group ( $p=0.7)$. Therefore, the mean improvement in the symptoms' severity scores and physical function scores from baseline was $1.33 \pm 1.01$ in the TLIF 


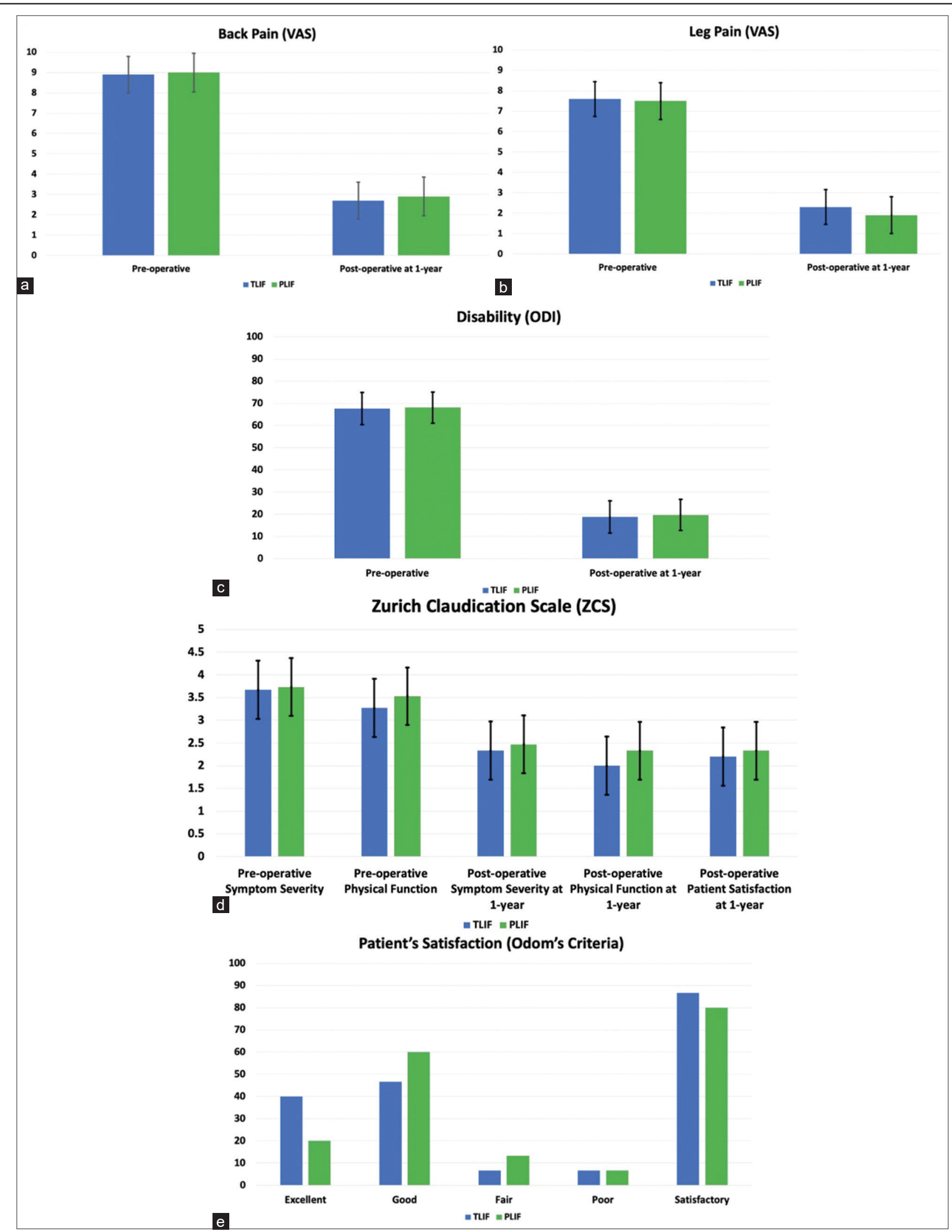

Figure 2: Bar graphs depicting the mean pre-operative and 1-year post-operative back pain scores (a; visual analog scale), leg pain (b; visual analog scale), (a; visual analog scale), leg pain (b; visual analog scale), disability (ODI) 38 scores (c), Zurich claudication scores (d), and patient satisfaction according to Odom's criteria (e) in each treatment group

group versus $1.27 \pm 0.93$ in the PLIF group $(p=0.9)$ and $1.27 \pm 0.77$ in the TLIF group versus $1.2 \pm 0.75$ in the PLIF group $(p=0.8)$. There was no significant difference in the post-operative patients' satisfaction according to Odom's criteria between both groups $(p=0.6)$. About $86.7 \%$ of the TLIF group patients were satisfied (excellent or good) compared to only $80 \%$ in the PLIF group patients (Table 2). 
Table 2: Total hospital costs and patients' reported outcome measures

\begin{tabular}{llll}
\hline Parameter & TLIF group & PLIF group & p-value \\
\hline Total cost (\$) & $641 \pm 22.4$ & $711.9 \pm 27.1$ & $<0.001^{*}$ \\
Back pain visual analog scale & & & \\
Mean pre-operative & $8.9 \pm 0.9$ & $9 \pm 1$ & 0.8 \\
Mean post-operative at 1 year & $2.7 \pm 0.9$ & $2.9 \pm 0.7$ & 0.5 \\
Mean change & $6.3 \pm 1.1$ & $6.1 \pm 1.1$ & 0.6 \\
Leg pain visual analog scale & & & \\
$\quad$ Mean pre-operative & $7.6 \pm 0.9$ & $7.5 \pm 1.1$ & 0.8 \\
Mean post-operative at 1 year & $2.3 \pm 0.8$ & $1.9 \pm 0.7$ & 0.2 \\
Mean change & $5.6 \pm 1$ & $5.7 \pm 0.9$ & 0.8 \\
Oswestry disability index & & & \\
Mean pre-operative & $67.73 \pm 7.77$ & $68.13 \pm 8.11$ & 0.9 \\
Mean post-operative at 1 year & $18.8 \pm 6.69$ & $19.73 \pm 5.84$ & 0.7 \\
Mean change & $48.93 \pm 9.2$ & $48.4 \pm 12.48$ & 0.9 \\
Zurich claudication scale & & & \\
Mean pre-operative symptoms severity & $3.67 \pm 0.47$ & $3.73 \pm 0.44$ & 0.7 \\
Mean post-operative symptoms severity & $2.33 \pm 0.79$ & $2.47 \pm 0.81$ & 0.6 \\
at 1 year & & & \\
Mean change in symptoms severity & $1.33 \pm 1.01$ & $1.27 \pm 0.93$ & 0.9 \\
Mean pre-operative physical function & $3.27 \pm 0.68$ & $3.53 \pm 0.5$ & 0.2 \\
Mean post-operative physical function at 1 year & $2 \pm 0.73$ & $2.33 \pm 0.7$ & 0.2 \\
Mean change in physical function & $1.27 \pm 0.77$ & $1.2 \pm 0.75$ & 0.8 \\
Post-operative patient satisfaction 1 year & $2.2 \pm 0.75$ & $2.33 \pm 0.79$ & 0.7 \\
Odom's criteria & & & \\
Excellent & $6(40)$ & $3(20)$ & 0.2 \\
Good & $7(46.7)$ & $9(60)$ & 0.5 \\
Fair & $1(6.7)$ & $2(13.3)$ & 0.5 \\
Poor & $1(6.7)$ & $1(6.7)$ & 1 \\
Satisfactory (excellent or good) & $13(86.7)$ & $12(80)$ & 0.6 \\
\hline Values are presented as the number of patients (\%) unless indicated otherwise. Mean values are reported \\
as the mean \pm SD. * denotes statistical significance. TLIF: Transforaminal lumbar interbody fusion, \\
PLIF: Posterior lumbar interbody fusion, \$: U.S. Dollars, VAS: Visual analog scale, ZCS: Zurich claudication \\
scale, ODI: Oswestry disability index. & & & \\
& & &
\end{tabular}

There was one case of nerve root injury while inserting the cage in the PLIF group while none in the TLIF group $(p=0.31)$, and there was one case in each group that had a dural tear which was repaired primarily with no post-operative CSF leak. Two patients developed post-operative wound infection in the PLIF group compared to only one patient in the TLIF group $(p=0.5)$. None of the patients developed a vascular injury, post-operative hematoma, or 30-day mortality (Figure 3 ). The mean operative duration for the TLIF group was $125.3 \pm 13.7$ min which was significantly shorter than the PLIF group which was $145.7 \pm 20.2 \mathrm{~min}(p<0.05)$. Moreover, there significantly less mean EBL for the TLIF group (315 $\pm 77 \mathrm{cc}$ ) compared to $453 \pm 90 \mathrm{cc}$ in the PLIF group $(p<0.001)$. There was no significant difference in the mean hospital stay in both the TLIF $(2.9 \pm 1.8$ days $)$ and PLIF group ( $3.1 \pm 1.3$ days) ( $p=0.7)$. Finally, at the 1-year follow-up images, there was no significant difference in the fusion rates in both groups $(p=0.5)$ and none of the patients developed a hardware failure (Table 3).

Table 3: Perioperative outcomes and complications

\begin{tabular}{llll}
\hline Parameter & TLIF group & PLIF group & p-value \\
\hline Mean duration of operation (min) & $125.3 \pm 13.7$ & $145.7 \pm 20.2$ & $<0.05^{*}$ \\
Mean estimated blood loss (cc) & $315 \pm 77$ & $453 \pm 90$ & $<0.001^{*}$ \\
Mean hospital stay (days) & $2.9 \pm 1.8$ & $3.1 \pm 1.3$ & 0.7 \\
Complications & & & \\
Dural tear & $1(6.7)$ & $1(6.7)$ & 1 \\
Root injury & 0 & $1(6.7)$ & 0.3 \\
Infection & $1(6.7)$ & $2(13.3)$ & 0.5 \\
Hematoma & 0 & 0 & 1 \\
Failure of fusion at 1 year & $1(6.7)$ & $2(13.3)$ & 0.5 \\
\hline
\end{tabular}

Values are presented as the number of patients (\%) unless indicated otherwise. Mean values are reported as the mean \pm SD. *denotes statistical significance. TLIF: Transforaminal lumbar interbody fusion, PLIF: Posterior lumbar interbody fusion, min: Minutes, cc: Cubic centimeter.

\section{Discussion}

This prospective randomized study, which included 33 patients with single-level lumbar spondylolisthesis, showed no clinical or radiographic outcome difference between TLIF and PLIF. As compared with the PLIF, the TLIF was associated with significantly less cost, less operative blood loss, and shorter operative time.

Many systematic reviews, meta-analysis, prospective, and retrospective studies were conducted in an attempt to compare the clinical and radiographic outcomes of TLIF and PLIF for the treatment of spondylolisthesis [3], [10], [11], [12], [14], [15], [16], [17], [18], [19], [20], [21], [22], [23], [24], [25], [26], [27]. Unfortunately, there was no study comparing them in terms of their costs. The novelty of this study is to compare the costs of doing such surgeries in a governmental run hospital in a lower-middle-/lowerincome nation to the reported ones from higher-income nations. Furthermore, we conducted a review of literature to see if this low cost in LMIC impacted the clinical and radiographic outcomes.

Interbody fusion techniques were developed to address several theoretical advantages in regard to the biophysics of the spinal column, namely, by attempting to restore the optimal disc space height and sagittal balance, also creating tension on the bone graft and facilitating the fusion by enhancing the blood supply from the adjacent endplates due to compressive forces [4]. The PLIF technique gained popularity with several indications including degenerative disc diseases, spondylolisthesis, spondylosis, and bilateral disc herniation [4], however, to obtain access using this technique, the dural sac has to be retracted off the midline, which can lead to nerve damage and neuropathic pain development, this leads to the development of the TLIF technique to eliminate the need for retraction of the dural sheath being lateral in position to the vertebral foramen [5].

\section{Primary Outcome}

In this study, we observed a significantly less total cost in the TLIF group ( $\$ 641 \pm 22.4)$ compared to the PLIF group $(\$ 711.9 \pm 27.1)(p<0.001)$. This difference can be attributed to the shorter duration of surgery and the use of one instead of two cages. The operators involved in this study were questioned regarding their private practice reimbursement for such surgery and the total costs ranged \$1276.2-6366.3. On reviewing the literature, no study is directly comparing the TLIF and PLIF costs, however, we strikingly found that the total cost of both TLIF and PLIF surgeries in the authors' country (Egypt) even in the private practice setting is significantly 


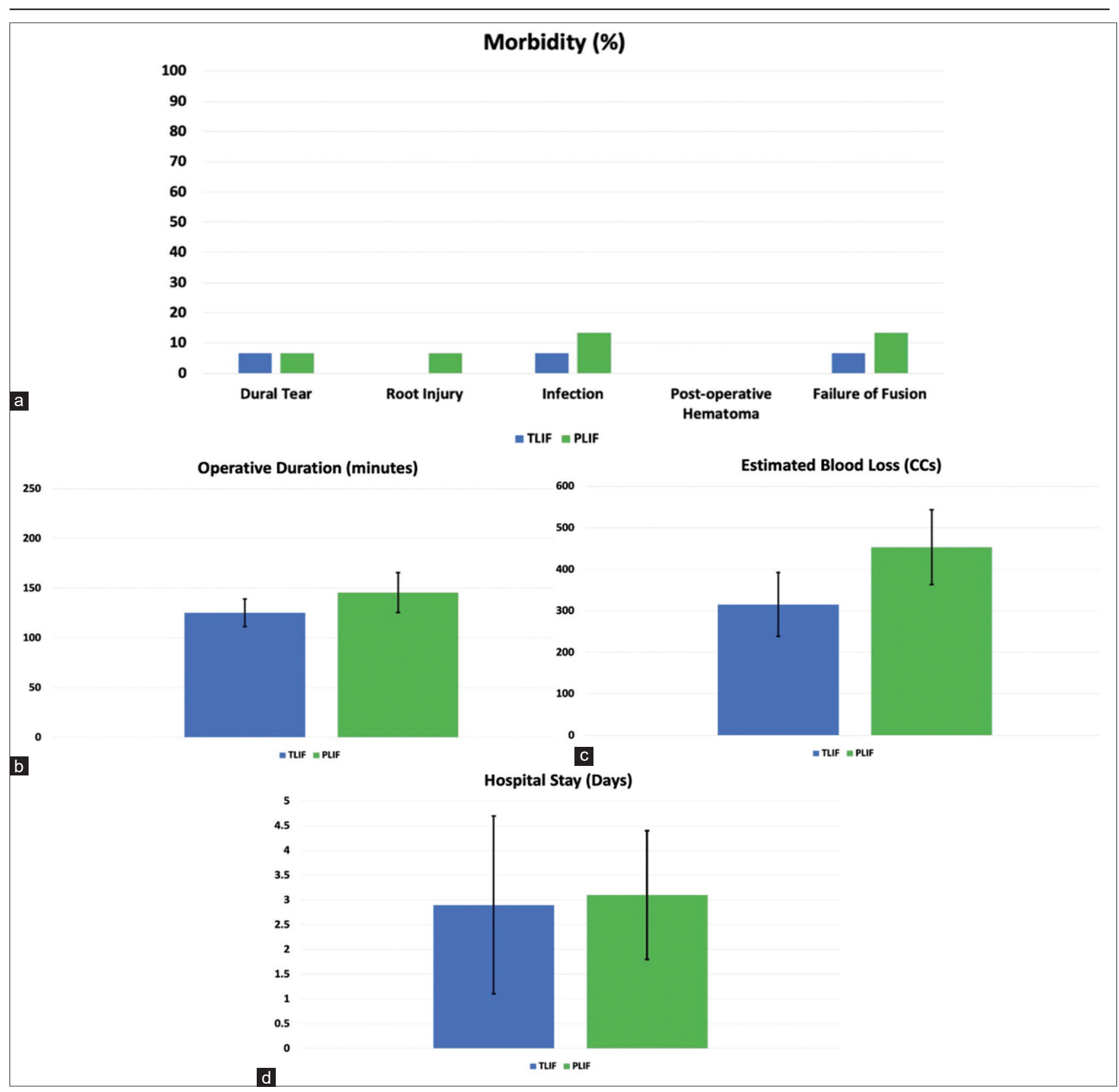

Figure 3: Bar graphs depicting percentage of morbidities (a), mean operative duration (b), mean estimated blood loss (c), and mean hospital length of stay (d)

less than what reported in the literature from higherincome nations (the United States, the United Kingdom, Denmark, Italy, and China) ranging \$12,825-47,029 in the TLIF and $\$ 14,081-86,112$ in the PLIF cases [28], [29], [30], [31], [32], [33], [34], [35], [36], [37], [38], [39], [40], [41], [42], [43]. Despite the significant difference, we cannot accurately compare our results with the literature due to marked heterogeneity in the methods used to calculate these costs among the studies reported.

\section{Secondary Outcomes PROM}

At 1-year post-surgery, there was a significant improvement in PROMs scores compared to the pre-operative scores in both groups, however, there was no significant difference among both treatment options. The mean back pain and leg pain VAS at 1-year after surgery had improved significantly from baseline in both groups but were non-significantly better in the TLIF group which is consistent with the results from other studies from higher-income nations [19], [23], [25], [26]. Similarly, the ODI at 1 year had significantly improved from baseline with slightly better scores in the TLIF group which is again similar to what is previously reported [19], [26]. Furthermore, there was a significant improvement in the symptoms' severity scores and physical function scores from baseline and was also slightly better in the TLIF group and this is the first study to compare between the TLIF and PLIF in 
terms of ZCQ scores. In regard to the patients' outcome satisfaction, $86.7 \%$ of the TLIF patients in this study reported either excellent or good outcomes compared to only $80 \%$ of the PLIF group. Other studies from higherincome nations reported excellent or good outcomes in $79-88.9 \%$ of their TLIF patients and $74-92.3 \%$ of PLIF patients [11], [22], [23], [24], [25], [27].

\section{Complications}

In terms of complications, nerve root injury occurred in $6.7 \%$ of the PLIF patients versus none in the TLIF group. In our literature review, this rate was $0-13.6 \%$ in the PLIF patients and $0-5.6 \%$ in the TLIF patients [10], [11], [14], [16], [17], [18], [19], [21], [22], [23], [24], [25], [26], [27]. About 6.7\% of each group of this study developed intraoperative dural tear which is a similar rate to that was reported in the literature from higher-income nations which range from $0 \%$ to $23.1 \%$ of the PLIF patients and from 0 to $10.4 \%$ of the TLIF patients [10], [11], [14], [15], [16], [17], [18], [19], [22], [23], [24], [26], [27]. Post-operative wound infection developed in $13.3 \%$ of the PLIF patients and only $6.7 \%$ of the TLIF patients. There is a slightly higher rate of infection in the PLIF patients of this study compared to what is reported in the literature $(0-7.2 \%)$, however, there is a similar rate to what is reported in the TLIF patients (0-7\%) [10], [11], [14], [16], [17], [18], [19], [23], [24], [26], [27]. None of this study patients developed graft malposition, vascular injury, post-operative hematoma, or 30-day mortality which is similar to what is reported in the literature with a graft malposition rate of $0-11.8 \%$ in the PLIF versus only $0-9.5 \%$ [10], [11], [15], [16], [17], [18], [19], [21], [24], [25], [26], [27], the vascular injury rate of $0-2.7 \%$ in the TLIF versus $0 \%$ in the PLIF [16], [22], a post-operative hematoma rate of $0 \%$ in the TLIF versus $0-2.5 \%$ in the PLIF [11], [17], [18], [22], and a mortality rate of $0-2.7 \%$ in the TLIF versus $0-3.7 \%$ in the PLIF [15], [16], [22].

\section{Operative and post-operative outcome}

\section{data}

In this study, The PLIF group had a significantly longer mean operative time (145.7 $\mathrm{min}$ ) compared to the TLIF group (125.3 min) which is similar to other studies which showed either a significant or a nonsignificantly longer operative time in the PLIF group (range, 124.8-241.6 $\mathrm{min}$ ) compared to the TLIF group (113.2-198 min) [11], [17], [18], [19], [21], [23], [26]. Furthermore, there was a significantly larger EBL in the PLIF group (453 ccs) compared to the TLIF group (315 ccs) and this is also consistent with what is reported in the literature with an EBL ranged 271.9 994 ccs in the PLIF versus 246.9-867 ccs in the TLIF [17], [18], [19], [21], [23], [24], [26]. The authors did not find a significant difference in terms of mean hospital stay between TLIF and PLIF groups (2.9 vs. 3.1, respectively) which is also similar to other reported studies with a range of 4-7.9 days in the TLIF patients and 4-8.8 days in the PLIF patients [10], [11], [17], [18], [21], [24].

\section{Radiographic outcomes}

There was no difference in the fusion rate between TLIF and PLIF groups (93.3\% versus $86.7 \%$, respectively) and also what is reported in the literature with a $91.9-100 \%$ fusion rate in the TLIF patients and $88.9-100 \%$ in the PLIF patients [10], [15], [16], [17], [19], [21], [22], [24], [25], [26], [27]. None of the cases had a failure of the hardware or screw loosening during the follow-up period. Similarly, the literature showed a rate of hardware failure or screw loosening ranging from $0 \%$ to $6.1 \%$ in the TLIF patients and $0-7.3 \%$ in the PLIF patients [10], [11], [15], [18], [19], [21], [25], [26].

\section{Cost versus complications}

As observed, there is a marked gap in the costs of the TLIF and PLIF surgeries in the authors' country (lower-middle-income country) compared to higher-income nations. Furthermore, the use of the low-cost hardware that was used in this study did not show any increased complication rates or differences in the clinical or the radiographic outcomes compared to the current literature from higher-income nations. However, we have to put into consideration that the gross national income per capita in the countries that reported the costs of these surgeries ranged from $\$ 16,740$ to 65,880 compared to only $\$ 11,810$ in the authors' country which might explain this gap in the costs [44].

\section{Limitations}

One of the main limitations of this study is the lack of patients' computerized randomization; however, this was addressed by closed envelope patients' randomization by a blinded person to the study. There is also a marked heterogenicity in the studies that reported the costs of the TLIF or PLIF in terms of the way of cost calculation, exclusion factors, or difference in the factors that determine the costs as well as the difference in the term costs and charges of surgery; nevertheless, this is the first study to directly compare the costs of the TLIF and PLIF. Finally, the sample size was only 33 patients, however, using the hospital stay cost as the primary outcome endpoint. Based on the observed means and S.D. in our sample, we observed large effect size (Cohen's $d=0.65$ ) on post hoc analysis. The observed power using a twotailed alpha of 0.05 and an equally divided sample of 30 participants was 0.95 . 


\section{Conclusion}

There is a marked gap between the cost of TLIF and PLIF in lower-income nations compared to the reported costs in the literature from higherincome nations with no difference in terms of clinical and radiographic outcomes. On comparing PLIF and TLIF, both of them achieved similar fusion rates and clinical satisfaction in the management of lumbar spondylolisthesis. Although the TLIF group was associated with more improvement in the back pain VAS, ODI, and ZCS, there was no statistical significance between both groups. Furthermore, the TLIF group was significantly better in terms of total costs, operative time, and blood loss.

\section{Acknowledgment}

Special thanks to Dr. Amany Ahmed for her help in the study statistics.

\section{References}

1. Försth P, Ólafsson G, Carlsson T, Frost A, Borgström F, Fritzell P, et al. A randomized, controlled trial of fusion surgery for lumbar spinal stenosis. N Engl J Med. 2016;374(15):1413-23. https:// doi.org/10.1056/nejmoa1513721

PMid:27074066

2. La Rosa G, Conti A, Cacciola F, Cardali S, La Torre D, Gambadauro NM, et al. Pedicle screw fixation for isthmic spondylolisthesis: Does posterior lumbar interbody fusion improve outcome over posterolateral fusion? J Neurosurg. 2003;99(2):143-50. https://doi.org/10.3171/spi.2003.99.2.0143 PMid: 12956455

3. De Kunder SL, van Kuijk SM, Rijkers K, Caelers IJ, van Hemert WL, de Bie RA, et al. Transforaminal lumbar interbody fusion (TLIF) versus posterior lumbar interbody fusion (PLIF) in lumbar spondylolisthesis: A systematic review and meta-analysis. Spine J. 2017;17(11):1712-21. https://doi. org/10.1016/j.spinee.2017.06.018

PMid:28647584

4. Cloward RB. The treatment of ruptured lumbar intervertebral discs by vertebral body fusion. I. Indications, operative technique, after care. J Neurosurg. 1953;10(2):154-68. https:// doi.org/10.3171/jns.1953.10.2.0154

PMid:13035484

5. Harms J, Rolinger H. A one-stager procedure in operative treatment of spondylolistheses: Dorsal traction-reposition and anterior fusion. Z Orthop Ihre Grenzgeb. 1982;120(3):343-7. PMid:7113376

6. Harms J, Jeszenszky D. Die posteriore, lumbale, interkorporelle fusion in unilateraler transforaminaler Technik. Oper Orthop Traumatol. 1998;10(2):90-102. https://doi.org/10.1007/ s00064-006-0112-7

\section{PMid:17332991}

7. Cole CD, McCall TD, Schmidt MH, Dailey AT. Comparison of low back fusion techniques: Transforaminal lumbar interbody fusion (TLIF) or posterior lumbar interbody fusion (PLIF) approaches. Curr Rev Musculoskelet Med. 2009;2(2):118-26. https://doi. org/10.1007/s12178-009-9053-8

\section{PMid: 19468868}

8. Mura PP, Costaglioli M, Piredda M, Caboni S, Casula S. TLIF for symptomatic disc degeneration: A retrospective study of 100 patients. Eur Spine J. 2011;20(1):S57-60. https://doi. org/10.1007/s00586-011-1761-2

PMid:21461695

9. Hee HT, Castro FP, Majd ME, Holt RT, Myers L. Anterior/ posterior lumbar fusion versus transforaminal lumbar interbody fusion: Analysis of complications and predictive factors. J Spinal Disord. 2001;14(6):533-40. https://doi. org/10.1097/00002517-200112000-00013

PMid:11723406

10. Humphreys SC, Hodges SD, Patwardhan AG, Eck JC Murphy RB, Covington LA. Comparison of posterior and transforaminal approaches to lumbar interbody fusion. Spine (Phila Pa 1976). 2001;26(5):567-71. https://doi. org/10.1097/00007632-200103010-00023 PMid:11242386

11. Park JS, Kim YB, Hong HJ, Hwang SN. Comparison between posterior and transforaminal approaches for lumbar interbody fusion. J Korean Neurosurg Soc. 2005;37:340-4.

12. Sakeb N, Ahsan K. Comparison of the early results of transforaminal lumbar interbody fusion and posterior lumbar interbody fusion in symptomatic lumbar instability. Indian J Orthop. 2013;47(3):255-63. https://doi. org/10.4103/0019-5413.111484 PMid:23798756

13. Schulz KF, Altman DG, Moher D, CONSORT Group. CONSORT 2010 statement: Updated guidelines for reporting parallel group randomised trials. BMJ. 2010;340:c332. https://doi.org/10.1136/ bmj.c332

\section{PMid:20332509}

14. Al Barbarawi MM, Audat ZM, Allouh MZ. Analytical comparison study of the clinical and radiological outcome of spine fixation using posterolateral, posterior lumber interbody and transforaminal lumber interbody spinal fixation techniques to treat lumber spine degenerative disc disease. Scoliosis. 2015;10:17. https://doi.org/10.1186/s13013-015-0040-0 PMid:26136814

15. Asil K, Yaldiz C. Retrospective comparison of radiological and clinical outcomes of PLIF and TLIF techniques in patients who underwent lumbar spinal posterior stabilization. Medicine (Baltimore). 2016;95(17):e3235. https://doi.org/10.1097/ md.0000000000003235

PMid:27124016

16. Audat Z, Moutasem O, Yousef K, Mohammad B. Comparison of clinical and radiological results of posterolateral fusion, posterior lumbar interbody fusion and transforaminal lumbar interbody fusion techniques in the treatment of degenerative lumbar spine. Singapore Med J. 2012;53(3):183-7. https://doi. org $/ 10.1055 / \mathrm{b}-0036-132177$

PMid:22434292

17. Cheng $\mathrm{X}$, Zhang $\mathrm{K}$, Sun $\mathrm{X}$, Zhao C, Li H, Ni B, et al. Clinical and radiographic outcomes of bilateral decompression via a unilateral approach with transforaminal lumbar interbody fusion for degenerative lumbar spondylolisthesis with stenosis. Spine J. 2017;17(8):1127-33. https://doi.org/10.1016/j. spinee.2017.04.011

PMid:28416439 
18. De Kunder SL, Rijkers K, van Hemert WL, Willems PC, ter Laak-Poort MP, van Santbrink H. Transforaminal versus posterior lumbar interbody fusion as operative treatment of lumbar spondylolisthesis, a retrospective case series. Interdiscipl Neurosurg. 2016;5:64-8. https://doi.org/10.1016/j. inat.2016.07.001

19. Han S, Xiao Q, Zhu GT, Dai J, Tang X, Sun HL. Comparison Between Transforaminal Lumbar Interbody Fusion and Posterior Lumbar Interbody Fusion in Treatment of Lumbar Spondylolisthesis; 2016. Available from: http://www.paper/ Comparison-between-transforaminal-lumbar-interbody-HanXiao/cb1820506f704024ad93deb8af9c7ea6ba905b66. [Last accessed on 2020 Nov 01]. https://doi.org/10.1201/b16155-33

20. Lan T, Hu SY, Zhang YT, Zheng YC, Zhang R, Shen Z, et al. Comparison between posterior lumbar interbody fusion and transforaminal lumbar interbody fusion for the treatment of lumbar degenerative diseases: A systematic review and meta-analysis. World Neurosurg. 2018;112:86-93. https://doi. org/10.1016/j.wneu.2018.01.021

PMid:29367001

21. Lee N, Kim KN, Yi S, Ha Y, Shin DA, Yoon DH, et al. Comparison of outcomes of anterior, posterior, and transforaminal lumbar interbody fusion surgery at a single lumbar level with degenerative spinal disease. World Neurosurg. 2017;101:21626. https://doi.org/10.1016/j.wneu.2017.01.114 PMid:28189865

22. Li L, Liu Y, Zhang P, Lei T, Li J, Shen Y. Comparison of posterior lumbar interbody fusion with transforaminal lumbar interbody fusion for treatment of recurrent lumbar disc herniation: A retrospective study. J Int Med Res. 2016;44:1424-9. https:// doi.org/10.1177/0300060516645419 PMid:27811052

23. Liu J, Deng H, Long $X$, Chen $X, X u R$, Liu Z. A comparative study of perioperative complications between transforaminal versus posterior lumbar interbody fusion in degenerative lumbar spondylolisthesis. Eur Spine J. 2016;25(5):1575-80. https://doi. org/10.1007/s00586-015-4086-8

PMid:26126415

24. Mehta VA, McGirt MJ, Garcés Ambrossi GL, Parker SL, Sciubba DM, Bydon A, et al. Trans-foraminal versus posterior lumbar interbody fusion: Comparison of surgical morbidity. Neurol Res. 2011;33(1):38-42. https://doi.org/10.1179/0161641 $10 \times 12681290831289$ PMid:20546682

25. Yan D, Pei F, Li J, Soo C. Comparative study of PILF and TLIF treatment in adult degenerative spondylolisthesis. Eur Spine J. 2008;17(10):1311-6. https://doi.org/10.1007/ s00586-008-0739-1

PMid:18685873

26. Yang EZ, Xu JG, Liu XK, Jin GY, Xiao W, Zeng BF, et al. An RCT study comparing the clinical and radiological outcomes with the use of PLIF or TLIF after instrumented reduction in adult isthmic spondylolisthesis. Eur Spine J. 2016;25(5):1587-94. https://doi. org/10.1007/s00586-015-4341-z PMid:26649555

27. Zhuo X, Hu J, Li B, Sun H, Chen Y, Hu Z. Comparative study of treating recurrent lumbar disc protrusion by three different surgical procedures. Zhongguo Xiu Fu Chong Jian Wai Ke Za Zhi. 2009;23(12):1422-6.

PMid:20073301

28. Adogwa O, Parker SL, Davis BJ, Aaronson O, Devin C, Cheng JS, et al. Cost-effectiveness of transforaminal lumbar interbody fusion for Grade I degenerative spondylolisthesis. J Neurosurg Spine. 2011;15(2):138-43. https://doi. org/10.3171/2011.6.spine10562a

PMid:21529203
29. Andres TM, Park JJ, Ricart Hoffiz PA, McHugh BJ, Warren DT, Errico TJ. Cost analysis of anterior-posterior circumferential fusion and transforaminal lumbar interbody fusion. Spine J. 2013;13(6):651-6. https://doi.org/10.1016/j.spinee.2012.11.055 PMid:23353002

30. Carreon LY, Glassman SD, GhogawalaZ, Mummaneni PV, McGirt MJ, Asher AL. Modeled cost-effectiveness of transforaminal lumbar interbody fusion compared with posterolateral fusion for spondylolisthesis using N(2)QOD data. J Neurosurg Spine. 2016;24(6):916-21. https://doi.org/10.3171/2015.10. spine15917

PMid:26895529

31. Christensen A, Høy K, Bünger C, Helmig P, Hansen ES, Andersen $\mathrm{T}$, et al. Transforaminal lumbar interbody fusion vs. posterolateral instrumented fusion: Cost-utility evaluation along sidean RCT with a 2-yearfollow-up. Eur Spine J. 2014;23(5):113743. https://doi.org/10.1007/s00586-014-3238-6 PMid:24557326

32. Fei H, Xu J, Wang S, Xie Y, Ji F, Xu Y. Comparison between posterior dynamic stabilization and posterior lumbar interbody fusion in the treatment of degenerative disc disease: A prospective cohort study. J Orthop Surg Res. 2015;10:87. https://doi.org/10.1186/s13018-015-0231-7 PMid:26031745

33. Gandhoke GS, Shin HM, Chang YF, Tempel Z, Gerszten PC, Okonkwo DO, et al. A cost-effectiveness comparison between open transforaminal and minimally invasive lateral lumbar interbody fusions using the incremental cost-effectiveness ratio at 2-year follow-up. Neurosurgery. 2016;78(4):585-95. https:// doi.org/10.1227/neu.0000000000001196 PMid:26726969

34. Godil SS, Parker SL, Zuckerman SL, Mendenhall SK, McGirt MJ. Accurately measuring the quality and effectiveness of cervical spine surgery in registry efforts: Determining the most valid and responsive instruments. Spine J. 2015;15(6):1203-9. https://doi. org/10.1016/j.spinee.2013.07.444 PMid:24076442

35. Lucio JC, Vanconia RB, Deluzio KJ, Lehmen JA, Rodgers JA, Rodgers W. Economics of less invasive spinal surgery: An analysis of hospital cost differences between open and minimally invasive instrumented spinal fusion procedures during the perioperative period. Risk Manag Healthc Policy. 2012;5:6574. https://doi.org/10.2147/rmhp.s30974 PMid:22952415

36. Parker SL, Adogwa O, Bydon A, Cheng J, McGirt MJ. Costeffectiveness of minimally invasive versus open transforaminal lumbar interbody fusion for degenerative spondylolisthesis associated low-back and leg pain over two years. World Neurosurg. 2012;78(1-2):178-84. https://doi.org/10.1016/j. wneu.2011.09.013

PMid:22120269

37. Parker SL, Mendenhall SK, Shau DN, Zuckerman SL, Godil SS, Cheng JS, et al. Minimally invasive versus open transforaminal lumbar interbody fusion for degenerative spondylolisthesis: Comparative effectiveness and cost-utility analysis. World Neurosurg. 2014;82(1-2):230-8. https://doi.org/10.1016/j. wneu.2013.01.041

PMid:23321379

38. Pelton MA, Phillips FM, Singh K. A comparison of perioperative costs and outcomes in patients with and without workers' compensation claims treated with minimally invasive or open transforaminal lumbar interbody fusion. Spine (Phila $\mathrm{Pa}$ 1976). 2012;37(22):1914-9. https://doi.org/10.1097/ brs.0b013e318257d490

PMid:22487713

39. Singh K, Nandyala SV, Marquez-Lara A, Fineberg SJ, Oglesby M, 
Pelton MA, et al. A perioperative cost analysis comparing single-level minimally invasive and open transforaminal lumbar interbody fusion. Spine J. 2014;14(8):1694-701. https://doi. org/10.1016/j.spinee.2013.10.053

PMid:24252237

40. Sulaiman WA, Singh M. Minimally invasive versus open transforaminal lumbar interbody fusion for degenerative spondylolisthesis grades 1-2: Patient-reported clinical outcomes and cost-utility analysis. Ochsner J. 2014;14(1):32-7. https://doi. org/10.1093/neuros/nyaa132

PMid:24688330

41. Vertuani S, Nilsson J, Borgman B, Buseghin G, Leonard C, Assietti $\mathrm{R}$, et al. A cost-effectiveness analysis of minimally invasive versus open surgery techniques for lumbar spinal fusion in Italy and the United Kingdom. Value Health. 2015;18(6):8106. https://doi.org/10.1016/j.jval.2015.05.002
PMid:26409608

42. Wang MY, Cummock MD, Yu Y, Trivedi RA. An analysis of the differences in the acute hospitalization charges following minimally invasive versus open posterior lumbar interbody fusion. J Neurosurg Spine. 2010;12(6):694-9. https://doi. org/10.3171/2009.12.spine09621

PMid:20515357

43. Whitecloud TS, Roesch WW, Ricciardi JE. Transforaminal interbody fusion versus anterior-posterior interbody fusion of the lumbarspine:Afinancialanalysis. JSpinalDisord. 2001;14(2):1003. https://doi.org/10.1097/00002517-200104000-00002 PMid:11285420

44. Gross National Income Per Capita. PPP (Current International \$) Data. Available from: https://www.data.worldbank.org/indicator/ NY.GNP.PCAP.PP.CD. [Last accessed on 2020 Nov 07]. 